\title{
Applications of 3D Potassium-Ion Pre-Intercalated \\ Graphene for Perovskite and Dye-sensitized Solar \\ Cells
}

Wei Wei, Meijia Li, and Yun Hang Hu*

Department of Materials Science and Engineering, Michigan Technological University, 1400

Townsend Drive, Houghton, MI 49931-1295, USA 


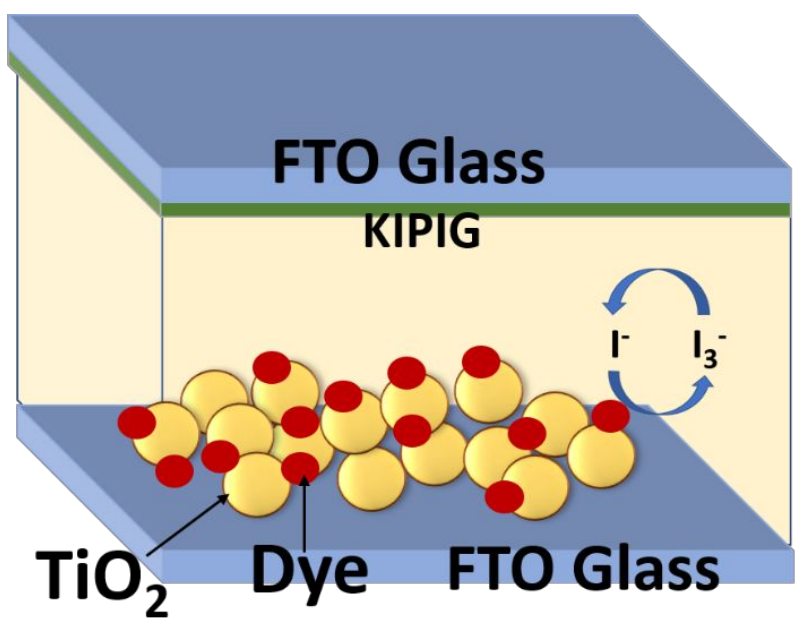

Figure S1. Schematic diagram of the structure of DSSC.

a

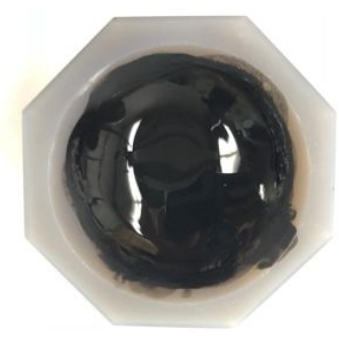

b

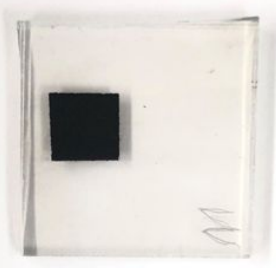

Figure S2. Photo of (a) carbon paste and (b) carbon counter electrode. 

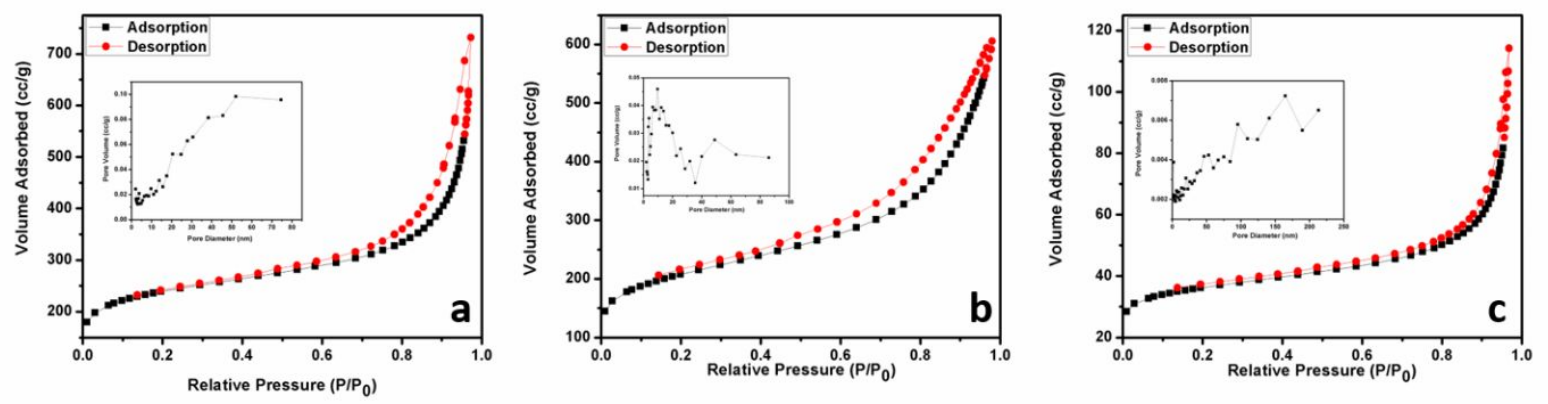

Figure S3. Adsorption/desorption curves of KIPIG with pore size distribution inset: (a) KIPIG500. (b) KIPIG-550. (c) KIPIG-600.

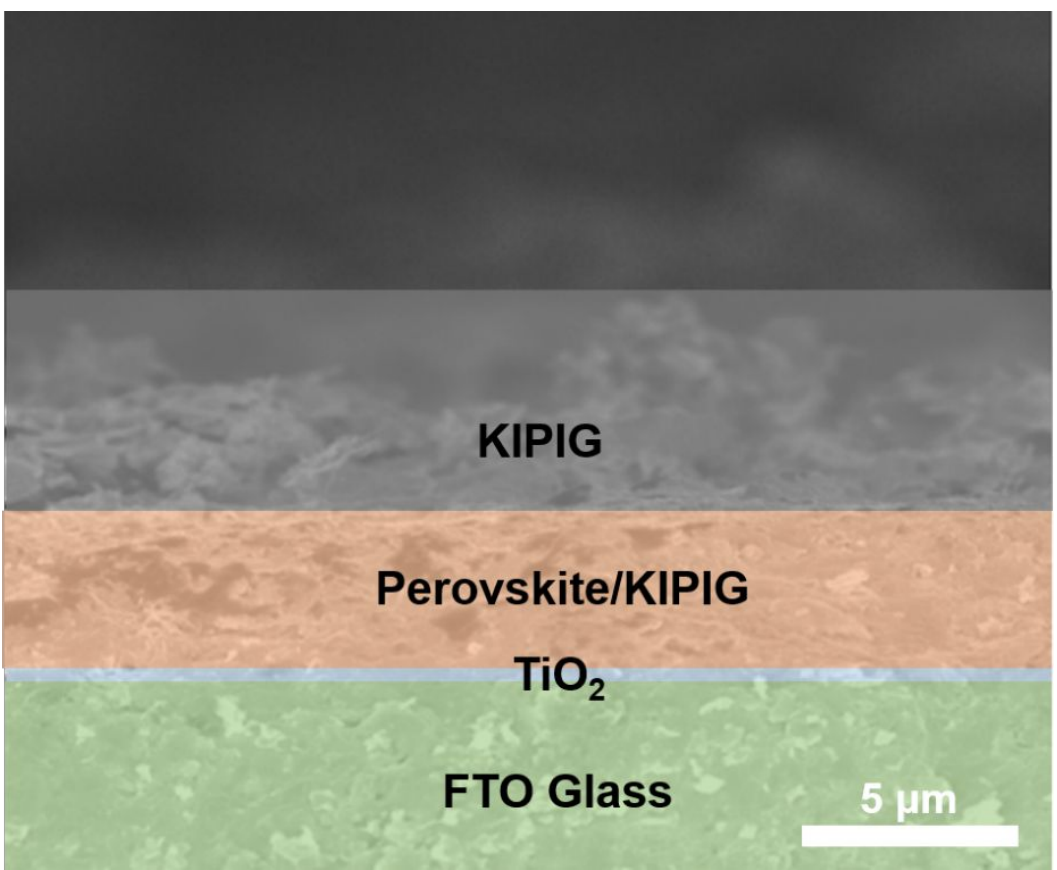

Figure S4. Cross-section FESEM image of KIPIG-based perovskite solar cell. 